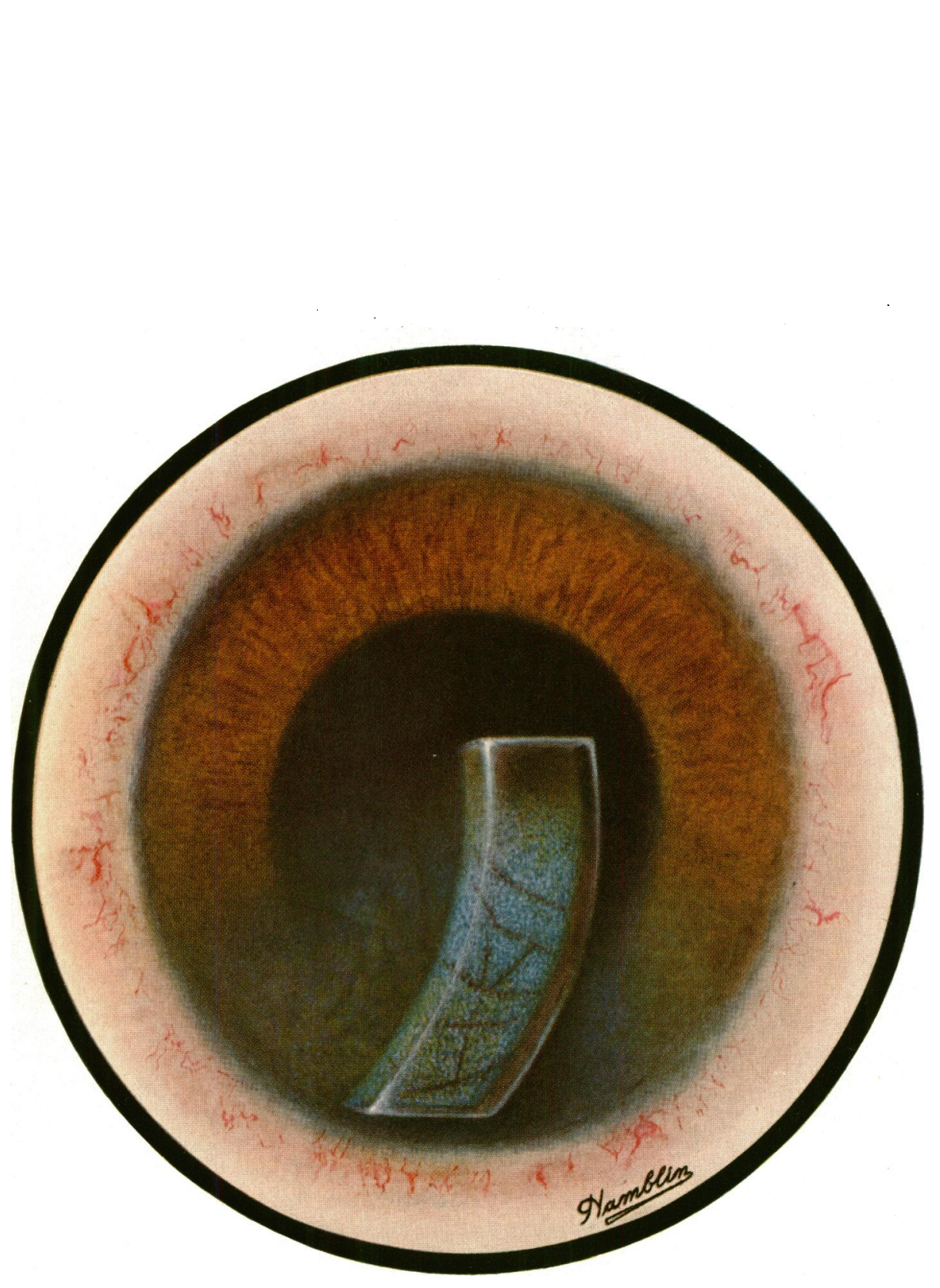

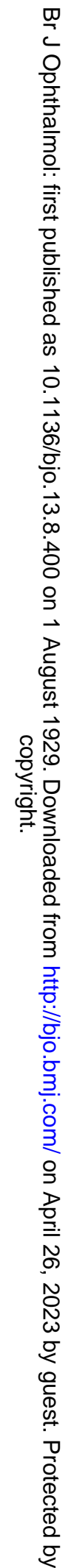




\title{
A CASE OF BLUE DEGENERATION OF THE CORNEA
}

\author{
BY \\ T. HARRISON BUTLER \\ BIRMINGHAM
}

JoHN P, aged 55 years, first came to The Birmingham Eye Hospital in April, 1924. He was complaining of irritation of the left eye and was found to have a chronic conjunctivitis which was treated with zinc sulphate. V.R. $\bar{c}-3 D . s p h .=6 / 9$. V.L. $\bar{c}-6 D$. sph. $0-1 \mathrm{D}$. cyl. $180^{\circ}=6 / 9$.

In $A$ pril, 1925, he was found to have some peripheral ulceration of the left cornea, very superficial.

In December, 1925, there was a recurrence of the peripheral ulceration. Flavine drops were used for a short time during 1925.

September, 1928, chronic conjunctivitis on both sides treated with zinc sulphate.

October, 1928, my House Surgeon noted a blue colouration of the left cornea in its lower aspect.

Examination with the slit-lamp reveals a very unusual change in the posterior eighth of the cornea in its lower half. The whole substance of the cornea at this depth has a quilted appearance which is seen in the drawing made by Messrs. Hamblin. The corneal tissue shows a coarse white granulation thickly dotted with bright blue flecks. The blue hue is accurately represented by "cyanine" in a paint box. The corneal prism has a superficial golden sheen, and in certain aspects there is a purple tinge in the upper part of the prism. These colours are probably contrast colours to the intense blue which is the dominant tone of the picture.

The visual acuity of the eye is now reduced to $6 / 18$.

\section{Progress}

At first the blue colour became more vivid, and the whole picture could be studied with an ordinary loupe under the illumination of a half-watt lamp. Examination with a dot-beam reflected from the posterior lens capsule showed the physical changes, but the blue colour could not be distinguished.

May, 1929. Considerable alterations have now taken place in the corneal picture as seen with the slit-lamp or with the loupe and half-watt lamp. The blue colour is less pronounced and now has a grey tinge. The quilting has entirely disappeared, the whole posterior part of the cornea having a coarse granulation. The acuity is now greater, 6/12 corrected. No changes have been detected in the right eye.

June, 1929. The blue colour has now faded to an ash grey. 


\title{
Discussion of the Case
}

The patient was shown to the Midland Ophthalmological Society, and to the Section of Ophthalmology of the Royal Society of Medicine. No member could recollect having seen any similar case, and as far as I have been able to ascertain nothing of the kind has been published. No mention was made of anything like it at Professor Vogt's course on the slit-lamp, nor is there any reference to it in his Atlas of slit-lamp microscopy. There is nothing approximating to the condition figured in "The Biomicroscopy of the Living Eye," published in the Transactions of the Société française d'O phtalmologie.*

I am bound to conclude that this case is unique, and that its cause and genesis is unknown. The fact that in certain lights there is a tendency to polychromatism, and that the blue is not seen by transmitted light makes it almost certain that the colour is an interference phenomenon, and is not due to any actual pigmentation.

Because the man is by trade a brass polisher it was suggested both at Birmingham and in London that the colour might be due to the action of copper. This view is quite untenable, for the changes produced by copper in the eye are well known and quite characteristic. The site of the change is not in Descemet's membrane but in the substantia propria deep in the cornea. Here a physical alteration has taken place which has produced a reflecting surface which causes interference of light in such wise that blue predominates. The hue suggests spectral rather than pigment blue.

\section{A RARE FORM OF DEVELOPMENTAL CATARACT}

\author{
BY \\ J. A; Conway and J. Masterton Thomson \\ GLASGOW
}

For two reasons the following case seems to us to be worthy of record. Firstly it is of considerable clinical and scientific interest, in that it shows a condition which we deem of rare occurrence, namely a partial cataract, which examination shows to be due to a very infrequently occurring cause. Secondly the case bears a medico-legal interest which is obvious.

The pertinent details of the case are as follows :-In June, 1926, a workman, aged 68 years, was knocking in the lids of some empty

\footnotetext{
*Examen microscopique des affections de la cornée au moyen de la lampe à fente, 1926.

Biomicroscopie de la Chambre Antérieure de l'Iris et du Corps Ciliare, 1928.
} 